\title{
SOLVEX - A COMPUTER PROGRAM FOR SIMULATION OF SOLVENT EXTRACTION PROCESSES
}

W. C. SCOTTEN
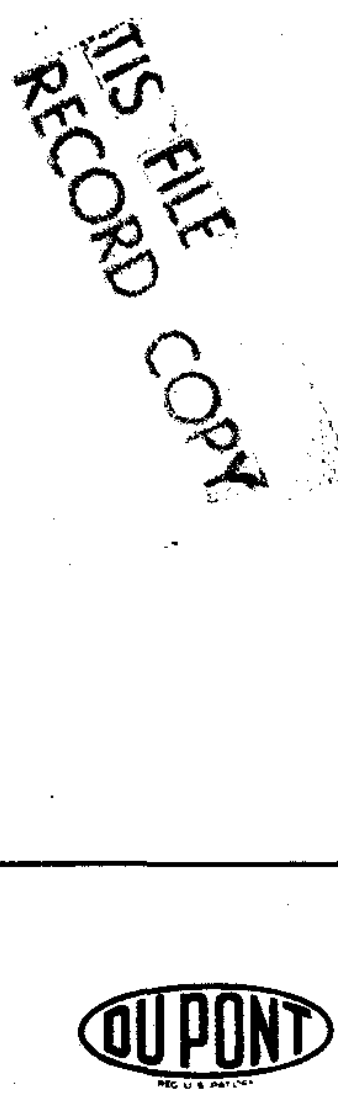

SAVANNAH RIVER LABORATORY AIKEN, SOUTH CAROLINA 29801 


\section{NOTICE}

This report was prepared as an account of-work sponsored by the United States Government. Neither the United States nor the United States Energy Research and Dovelopment Administration, nor any of their contractors, subcontractors, or their employees, makes any warranty, express or implied, or assumes any legal liability or responsibility for the accuracy, completeness or usefulness of any information, apparatus, product or process disclosed, or represents that its use would not infringe privately owned rights.

Printed in the United States of America

Available from

National Technical Information Service

U. S. Department of Commerce

5285 Port Royal Road

Springfield, Virginia 22161

Price: Printed Copy \$4.00; Microfiche $\$ 2.25$ 
DP-1391

Distribution Category: UC-32

\section{SOLVEX - A COMPUTER PROGRAM FOR SIMULATION OF SOLVENT EXTRACTION PROCESSES}

by

W. C. Scotten

Approved by

J. A. Porter, Superintendent Separations Technology Section Works Technical Department Savannah River Plant

Publication Date: September 1975

E. 1. DU PONT DE NEMOURS AND COMPANY SAVANNAH RIVER LABORATORY AIKEN, SOUTH CAROLINA 29801

PREPARED FOR THE U.S. ENERGY RESEARCH AND DEVELOPMENT ADMINISTAATION UNDER CONTRACT ATIO7.2\%-I 


\section{ABSTRACT}

SOLVEX is a FORTRAN IV computer program that simulates the dynamic behavior of solvent extraction processes conducted in mixer-settlers and centrifugal contactors. Two options permit terminating dynamic phases by time or by achieving steady state, and a third option permits artificial rapid close to steady state. Thus the program is well suited to multiple phases of dynamic problems and multiple input of steady state problems. Changes from the previous problem are the only inputs required for each succeeding problem. Distribution data can be supplied by twovariable third-power polynomial equations or by three-variable tables in any one of 16 different combinations involving phase concentrations or distribution coefficients (ratio of phase concentrations) or their logarithms. 
CONTENTS

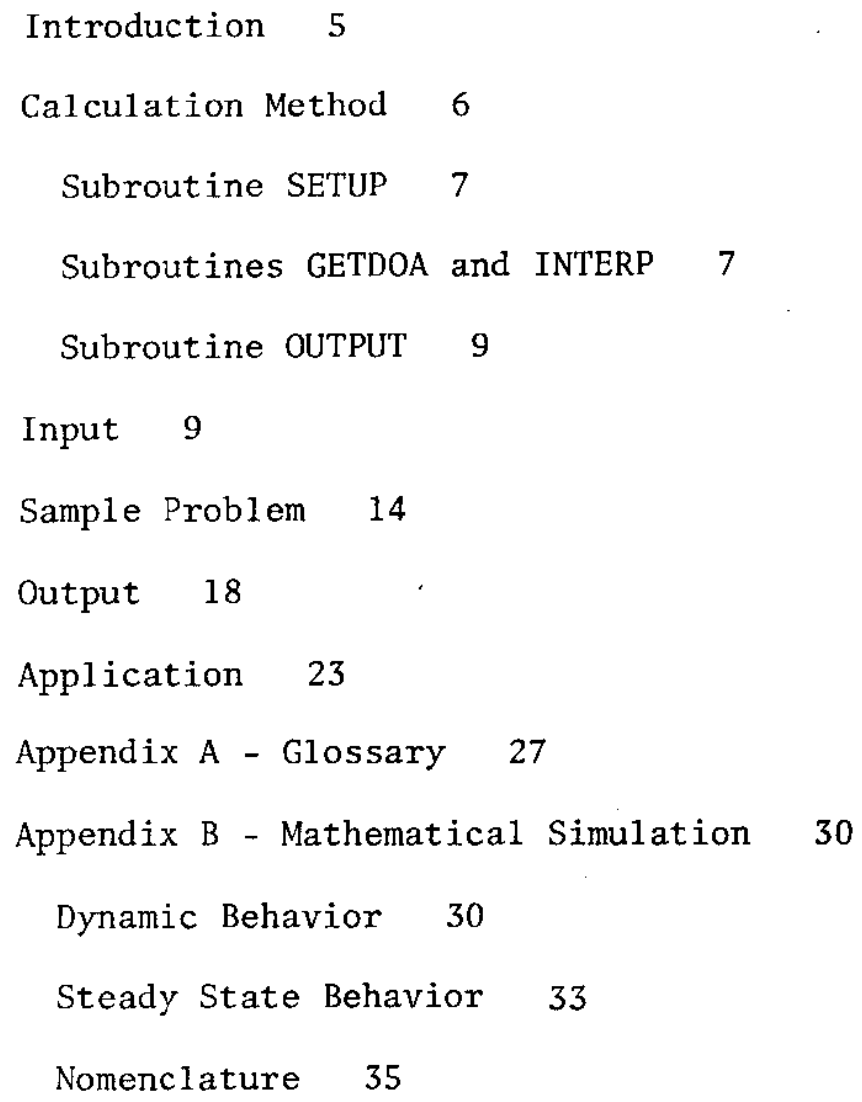




\section{SOLVEX - A COMPUTER PROGRAM FOR SIMULATION OF SOLVENT EXTRACTION PROCESSES}

\section{INTRODUCTION}

SOLVEX is a FORTRAN IV computer program that simulates the dynamic and steady state behavior of solvent extraction banks composed of either mixer-settlers or centrifugal contactors. Under one option, the program closes rapidly to steady state for the specified input conditions. Under two other options, various aspects of dynamic or transient behavior can be simulated, including startup, flow and concentration changes, and shutdown.

The program handles chemical systems with as many as five components with or without mutual dependence of the distribution of the components between organic and aqueous phases (dependence of distribution coefficients on a single reference component is not considered mutual dependence).

Distribution data may be expressed in the form of tables or cubic polynomial equations. The equations are limited to two variables (one reference component), but the tables may include two or three variables (one or two reference components) and, for three-variable tables, may apply to a specific concentration of an aqueous salting agent (third reference component). The dependent variable can be expressed as the organic phase concentration or the distribution coefficient itself, or as the natural logarithm of either. Similarly, the reference component(s) can be expressed as the concentration itself, or the logarithm of the concentration, in either the aqueous or organic phases. Finally, the distribution data for each component may be split into two concentration ranges with different methods of expressing the data in each.

The bank may consist of as many as 24 stages with the option of feeding both aqueous and organic streams to each stage. The organic phase can be withdrawn only from Stage 1 and the aqueous phase on1y from the highest numbered stage.

For steady state solutions, output results provide the aqueous and organic concentrations of each component leaving each stage and can provide as an option the aqueous, organic, and total inventories of each component in the bank if the mixer and settler volumes are provided. The definition of steady state involves meeting two criteria: change in bank inventory of each component must be less 
than $1 \%$ per hour, and instantaneous flow of each component out of the bank must be within $0.1 \%$ of the instantaneous flow into the bank.

For dynamic solutions, aqueous and organic concentrations of each component leaving the terminal stages and seven other selected stages are shown at time intervals selected by the user. The entire operation can be broken down into phases with different print intervals, feed rates, and feed concentrations. Another option provides a rapid close to steady state at any selected time as a preface to a transient behavior period. A complete inventory and material balance, including total flow in and out for each component in each phase, will also be printed at time intervals specified by the user.

The dynamic calculations are based on a variation of the so-called lumped parameter system; i.e., mixers are assumed to be well-mixed tanks, and each settler is assumed to be a series of we11-mixed zones or tanks overflowing one to another. As many as 50 settlers zones can be specified by the user.

The aqueous and organic volumes in the settlers are specified by the user and are assumed to be independent of flow rate. The specified mixer volume is split between aqueous and organic phases in proportion to the flow rate of each.

\section{CALCULATION METHOD}

The mathematical equations used to simulate the solvent extraction process are described in detail in Appendix B. For both dynamic and steady state options, the calculation proceeds from Stage 1 through the last stage specified by the user for successive time intervals, beginning at time zero with pure water and pure solvent in the bank. For steady state calculations, an arbitrary time interval of unity is used which has no relation to real time. In that case, "time" merely corresponds to the number of iterations to that point in the calculation. The calculation is based on the concept of we11-mixed tanks as described in the Introduction. The rate of change in the inventory of a given component in either the mixer or a settler zone is proportional to the flow of that component into the "tank" less the component flow out, assuming that the concentration leaving corresponds to the uniform concentration in the well-mixed tank. The differential equation describing that material balance is translated into finite difference form; input concentrations to the stage are taken as the output concentrations from adjacent stages during the previous time interval; and the equations are solved for the aqueous and organic exit concentrations during the current time interval by trialand-error iteration. Concentrations from the mixer and each settler zone are calculated before proceeding to the next stage. 
The calculations described above are performed in the main SOLVEX program. The main program also calls the other subroutines described briefly below:

Subroutine SETUP. This subprogram establishes flow rates throughout the bank from input data for feed rates and feed stages. This subroutine also establishes the integration time interval. Minimum holdup time is first determined as the holdup time for liquid in the smallest of these volumes: mixer aqueous and organic volumes and settler aqueous and organic zones. The integration time interval is then determined by multiplying this minimum time by a fraction TMULT provided by the user. The smaller the value of TMULT, the better the simulation, but the longer the computing time. The user must strike a compromise between simulation accuracy and computing time.

Subroutines GETDOA and INTERP. These subprograms supply the distribution coefficient $D$ relating concentrations of organic and aqueous phases in equilibrium with each other. GETDOA calls INTERP to interpolate within two- and three-variable tables. The options or methods of supplying this information are summarized in Figure 1. The dependent variable $u$ can be expressed as the distribution coefficient itself, the organic phase concentration, or the natural logarithm of either of the two. For simple two-variable relationships, the independent or reference variable $v$ can be either a concentration or the natural logarithm of the concentration of any one of the components in either the aqueous or organic phases (the phase is specified by another input described under INPUT, page 11). These two-variable relationships are identified by numbers in the shaded section of Figure 1 (Type 1 through Type 8 ). They can be supplied either as a table or as a polynomial equation of the form:

$$
u=\mathrm{A}+\mathrm{B} v+\mathrm{C} v^{2}+\mathrm{D} v^{3}
$$

The equation transforms to constant, linear, or quadratic form by equating appropriate coefficients to zero.

Relationships involving the dependent variable $u$ and two independent or reference variables $v$ and $z$ can be set up, but only in tabular from. Type 1 through Type 16 cover these combinations. As with the first reference variable, the second reference variable can be a concentration of any one of the components in either the aqueous or organic phases.

For both equations and tables, the data for a given component can be restricted for use above or below a specified value CMIN of the first reference concentration. When a third reference component is specified, the entire table applies to a specific aqueous concentration of a salting agent which must be greater than CMIN. 


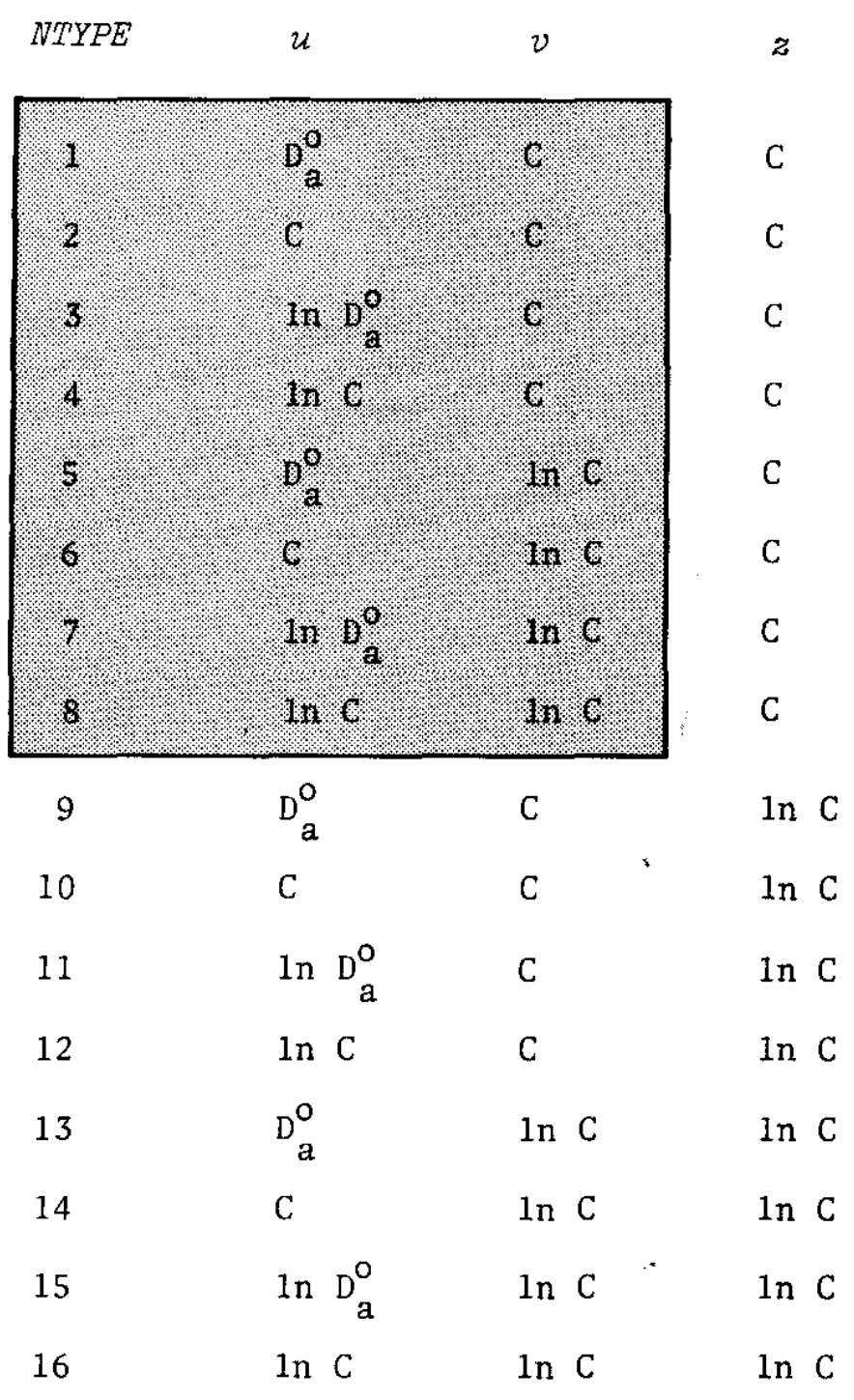

FIGURE 1. Allowable Methods of Expressing Distribution Data

Only combinations in shaded area can be used for equations. For components that do not transport into the organic phase, NTYPE $=0$ (on a No. 3 card).

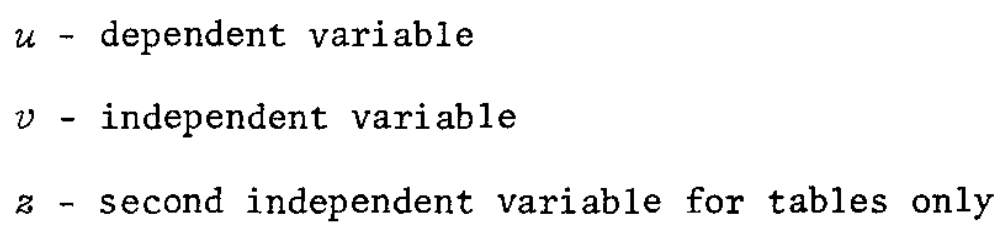


CMIN would now apply solely to the salting agent. Problems with a salting agent as a third reference component are more inflexible and must be set up with care because flow rates and feed concentrations of the salting agent must be made compatible with the distribution data tables. This is not the case when the salting agent is the second reference component in a three-variable table. In that case, the table will be properly interpolated as the concentration of salting agent changes with changes in flow rates and feed concentrations.

Subroutine OUTPUT. Program results are printed by this subroutine. Several options which can be exercised by the user are best explained by the various types of printout described under OUTPUT, page 18 .

\section{INPUT}

Input data are supplied on standard IBM cards. Card formats are shown in Figure 2, and the various types of cards are described below.

SIEADY STAFE PHOBLEMS

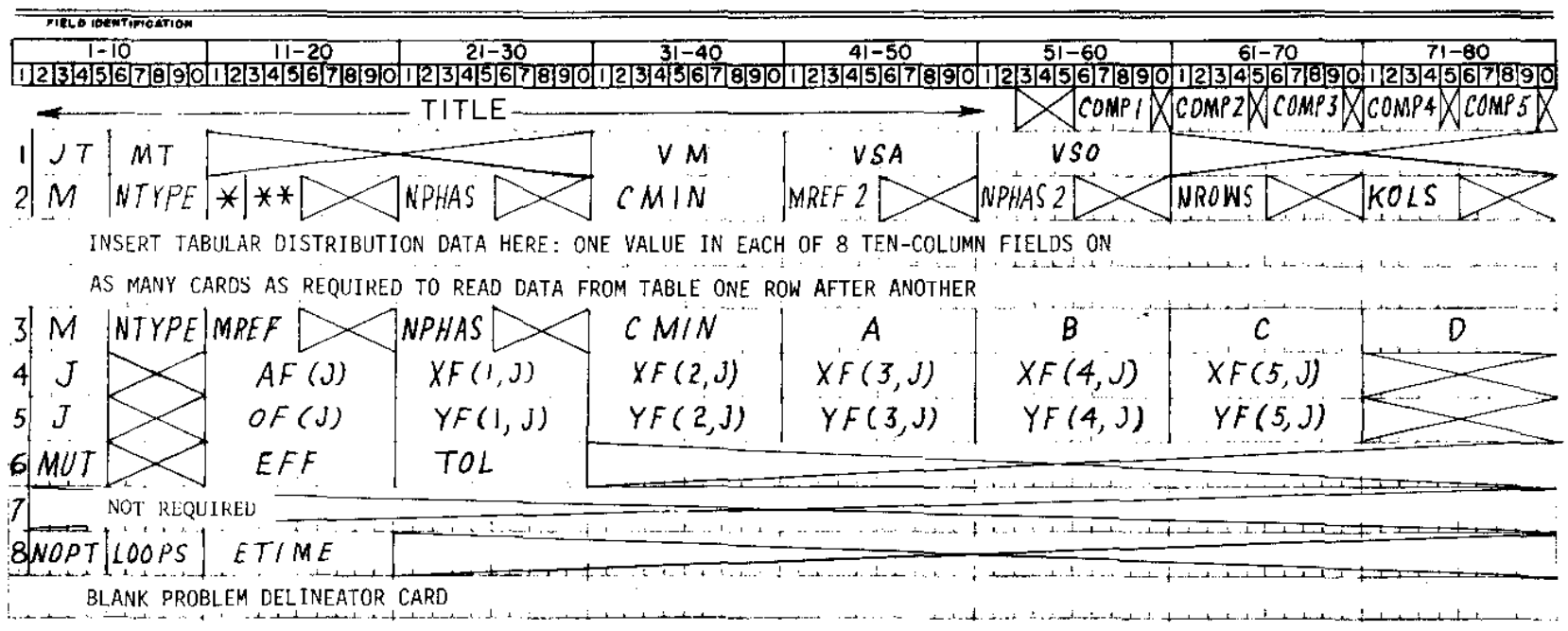

DYNAMIS, PROBLEMS

In addition to the card fields shown above for steady state, the card fields shown below must also be punched for dynamic problems:

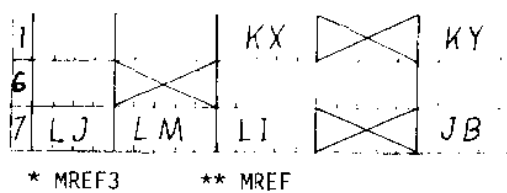

* MREF3 3 MREF

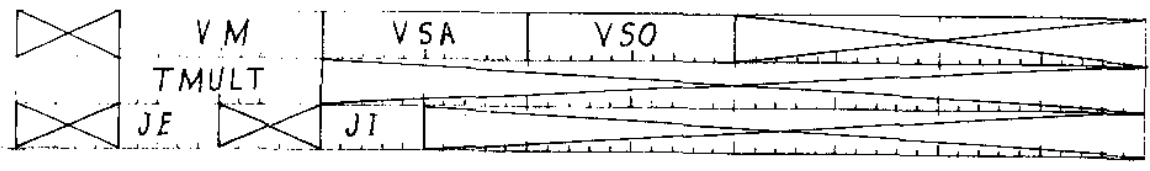

FIGURE 2. Input Data Card Formats 
Title card. This must be the first card in the data deck. The title applies to one dynamic problem or to a series of steady state problems. It consists of as many as 52 legal alphameric characters including blanks punched in Columns 1 through 52. The component names are also provided on this card. Each name can be four alphameric characters long including blanks, and the name for the first component must start in Column 56. Names for additional components begin in Columns $61,66,71$, and 76 successively for as many components as are involved. With the following exceptions, subsequent cards bear characteristic numbers in Column $l$ and can be in any order:

- Tabular distribution data cards, which must follow No. 2 cards, do not require characteristic numbers in Column 1, which can be occupied by the first digit of a data number.

- A No. 8 card must be provided for every problem and must be the last data card for that problem.

The program recognizes two types of data input numbers: whole or integer numbers which do not include a decimal point and decimal numbers which do include a decimal point. Integer numbers are entered in card fields that are 1 to 5 columns wide. These numbers must be right-justified within the field (must have no unused columns to the right of the number).

Decimal numbers are entered in card fields that are always 10 columns wide and can be punched anywhere within that field.

Definitions of the terms used in labeling card entries are given in Appendix A, Glossary.

No. 1 - Bank Card. This card provides the total number of stages JT and the total number of components MT. For steady state problems, no other entries on this card are required, but if inventory results are desired, the user should also provide mixer volume VM, aqueous settler volume VSA, and organic settler volume VSO. For dynamic problems, VM, VSA, and VSO are required, and in addition, the user must provide the number of aqueous and organic settler zones $\mathrm{KX}$ and $\mathrm{KY}$.

No. 2 - Tabuzar Data Control Card. Cards of this type provide program control information for reading and using tabular distribution data. The following information must be supplied for two-variable tables:

- Component number $M$ to which the data apply.

- Type of distribution data from Figure 1 (NTYPE). 
- Reference component number (MREF).

- Phase (aqueous or organic) in which the reference component concentration exists (NPHAS equals 0 for organic or 1 for aqueous).

- Minimum concentration CMIN for the reference concentration covered by the table (if left blank CMIN is assumed to be zero).

- Number of rows in the table (NROWS).

- Number of columns in the table (KOLS).

For three-variable tables, similar information for MREF2 and NPHAS2 must also be supplied for the second reference component (CMIN is not required for the second reference component). If MREF 3 is supplied, CMIN refers to the concentration of that component, and the entire table applies to a specific concentration of the MREF3 nontransportable salting agent which must be greater than CMIN.* This control card is followed by cards providing the tabular data. Data are punched on cards (eight values per card in 10-column fields) to fill successive rows of a table with the format shown in Figure 3.

For three-variable tables, the first row provides values for the second reference component (MREF2). The first position in the table labeled DUM must be filled with an unused dummy value $(0.0)$ or left blank on the card. The first entry in each succeeding row provides values for the first reference component with values for the dependent variable filling successive positions in the row. The second table row begins on the same card and in the card field following the last entry of the first table row.

For two-variable tables, the DUM and $z$ values are not required, and the data entries begin with the first value for the first reference component followed by the corresponding value of the dependent variable. Successive pairs of values are punched in the succeeding fields of the first card and continued on as many cards as required for the whole table. Thus, two-variable tables occupy only the first two columns of Figure 3 as shown by the shaded section.

* Problems with a salting agent as a third reference component are more inflexible and must be set up with care as described earlier under subroutines GETDOA and INTERP. 


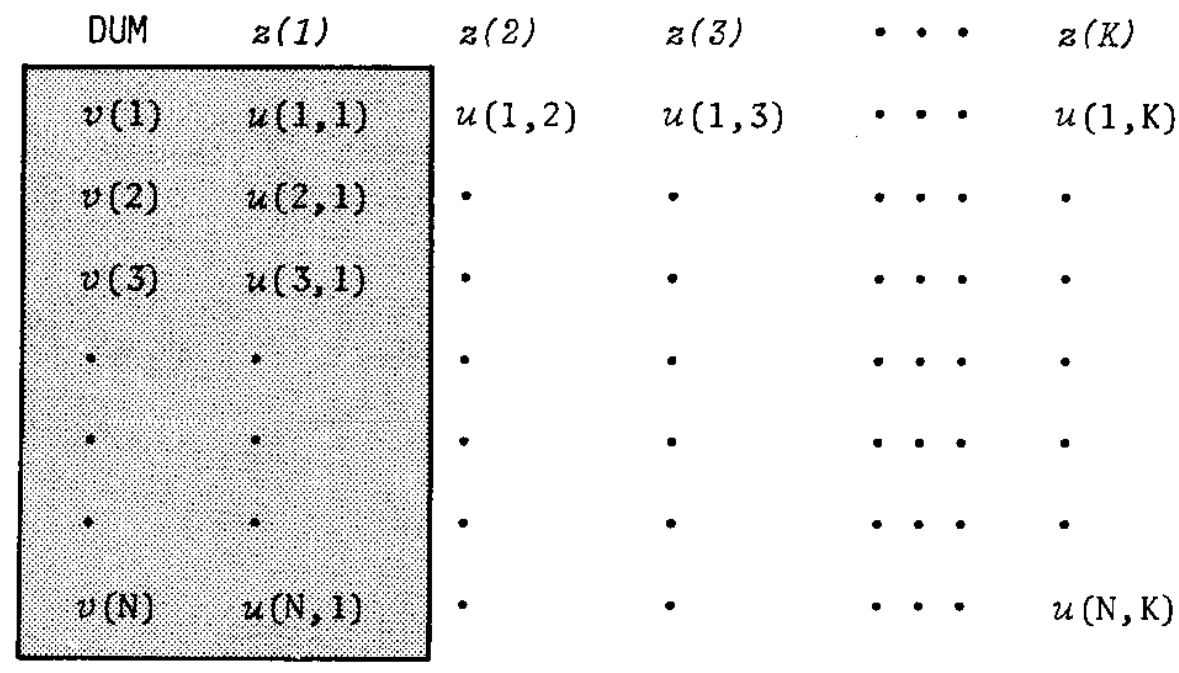

FIGURE 3. Tabular Data Format

Successive rows in this table do not correspond to successive input data cards, except by coincidence when the table has eight columns $(K=7)$.

$u$ - dependent variable

$v$ - first reference variable (MREF)

$z$ - second reference variable (MREF2)

DUM - dummy position

Format for two-variable tables is in shaded area.

$\mathrm{K}=\mathrm{KOLS}-1$

For two-variable tables, $\mathrm{N}=$ NROWS

For three-variable tables, $N=$ NROWS- 1 
A maximum of five tables are allowed: one for each of five components, or two for each of two components and one for a third component, etc.

No. 3 - Distribution Equation Control Card. Cards of this type provide coefficients and program control data to express distribution data in equation form. The entries M, NTYPE, MREF, NPHAS, and CMIN must be provided and serve the same functions as described for tabular data (No. 2 Cards). The A, B, C, and D entries provide the coefficients in a distribution equation of the form:

$$
u=\mathrm{A}+\mathrm{B} v+\mathrm{C} v^{2}+\mathrm{D} v^{3}
$$

Components that do not transport into the organic phase $\left(D_{a}^{o}=0\right)$ are assigned an NTYPE value of zero on a No. 3 card with no further card entries required. No. 2 cards should not be used for this purpose, nor should this be done by setting all equation coefficients to zero on a No. 3 card with an NTYPE greater than zero (excessive execution time).

No. 4 - Aqueous Feed Cards. The feed stage $J$, the feed rate $\mathrm{AF}(\mathrm{J})$, and component concentrations in the feed $\mathrm{XF}(\mathrm{M}, J)$ are provided on these cards. There can be as many cards as there are stages.

No. 5 - Organic Feed Cards. The format of these cards is the same as for the No. 4 cards, providing organic feed rate $\mathrm{OF}(\mathrm{J})$ and concentrations $\mathrm{YF}(\mathrm{M}, \mathrm{J})$ to the $\mathrm{Jth}$ stage.

No. 6 - Miscelzaneous Control Data Card. This card provides for mutual dependency of component distribution between phases (MUT $=1$ rather than 0 ), provides stage efficiency EFF and closing tolerance TOL, and for dynamic programs, provides the integration factor TMULT which must always be less than one. The function of these terms is explained in Appendix A, Glossary. For MUT $=0$ to be applicable, the reference component must have a lower component number than the component for which the distribution data apply. For MUT $=1$, distribution data for a given component can reference any other component. However, MUT $=1$ should be used only where necessary because of the greater computation time required.

No. 7 - Output Control Card. This card is not required for steady state calculations (although it can be used to get intermediate values in the iteration to steady state for debugging purposes; however, these values would have no dynamic meaning in the real world). For dynamic calculations, the program control value $\mathrm{LI}$ and the output control values $\mathrm{LJ}$, LM, JB, JE, and JI are provided on this card. These terms are explained in OUTPUT, page 20 and Appendix A, Glossary. 
No. 8 - Option Card. This card provides program options and program control data for the first option as tabulated below:

NOPT1 Dynamic calculation; phase terminated by executing in that phase a number of cycles equal to LOOPS or by reaching a process time equal to ETIME.

NOPT2 Dynamic calculation; phase terminated by reaching steady state; LOOPS and ETIME must not be provided.

NOPT3 Artificial rapid close to steady state. LOOPS and ETIME must not be provided; process time is reset to zero.

A No. 8 card must be provided for every dynamic phase and steady state problem and must be the last data card.

Delineation Cards. A single blank card must be inserted to delineate the end of each dynamic phase and each steady state problem.

\section{SAMPLE PROBLEM}

Figure 4 is a computer facsimile of the data read directly from cards for a problem that combines steady state and dynamic phases. The first card provides the title of the problem. The study explores the possibility of injecting acid at the 11th stage to enhance the separation of neptunium from uranium. Three of the five component labeling fields on the right side of the card are used to identify the acid, neptunium, and uranium (valence 6) components. 


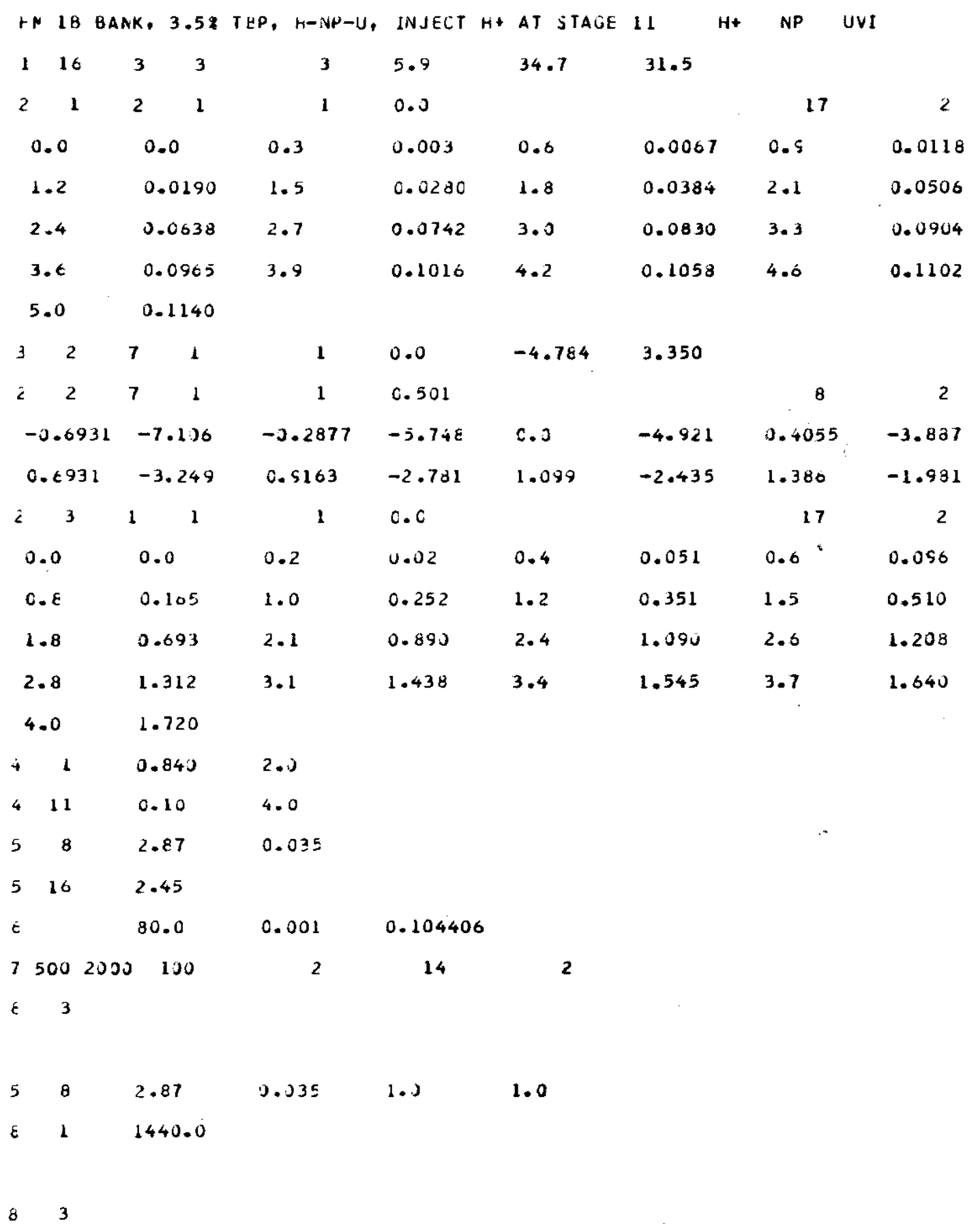

FIGURE 4. Computer Facsimile of Card Input Data 
The next card, Type 1 (Column 1), provides the following information:

$\mathrm{JT}=16$ stages

MT $=3$ components

$K X=3$ aqueous settler zones

$K Y=3$ organic settler zones

$V M=5.9$ 1iters mixer volume

VSA $=34.7$ 1iters aqueous settler volume

VSO $=31.5$ 1iters organic settler volume

The next card, Type 2, provides control information for reading tabular distribution data on the next 5 cards. The No. 2 card provides the following information:

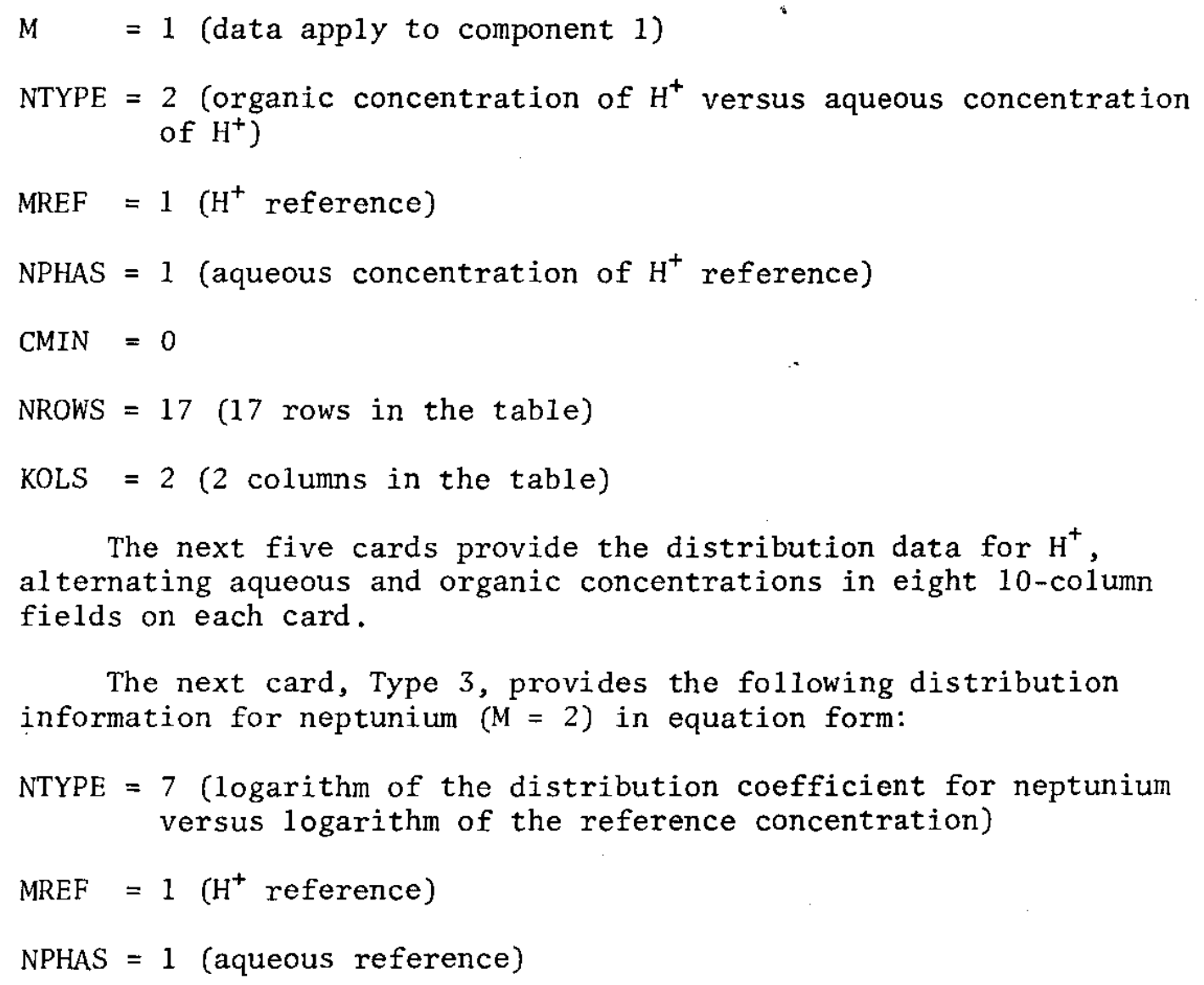
alternating aqueous and organic concentrations in eight 10-column fields on each card.

The next card, Type 3, provides the following distribution information for neptunium $(M=2)$ in equation form:

NTYPE $=7$ (logarithm of the distribution coefficient for neptunium versus logarithm of the reference concentration)

$\mathrm{MREF}=1\left(\mathrm{H}^{+}\right.$reference $)$

NPHAS $=1$ (aqueous reference) 
CMIN $=0$ (data apply down to zero reference concentration and up to CMIN on another card, if provided. Otherwise, unlimited application)

$$
\left.\begin{array}{l}
A=-4.784 \\
B=3.350
\end{array}\right\} \text { in } D=3.350 \text { In } H^{+}-4.784
$$

The next card, Type 2, provides control information for tabular distribution data for neptunium $(M=2)$ on the next two cards. The data are in the form NTYPE $=7$ and are good at aqueous $($ NPHAS $=1$ ) acid concentrations $(M R E F=1)$ greater than or equal to 0.501 mole per liter (this also limits the neptunium data presented earlier by equation to acid concentrations less than $0.501 \mathrm{M})$. The data are provided in a table of eight rows and two columns. The next two cards provide these data, alternating logarithms of $\mathrm{H}_{\mathrm{a}}^{+}$and $\mathrm{D}_{\mathrm{a}}^{\mathrm{O}}$.

The next No. 2 card and the following five cards provide tabular distribution data for uranium in the form NTYPE $=3$ (1n $\mathrm{D}_{\mathrm{a}}^{\mathrm{O}}$ versus reference concentration) with aqueous acid as the reference. Since CMIN $=0$ and no other cards are provided for uranium, the data apply over the whole range of concentration.

The next two No. 4 cards provide the following aqueous feed information:

$\begin{array}{ccccc}\text { Stage } & \text { Ziters/minute } & \frac{H^{+}}{\text {moles/liter }} & \frac{U(V I)}{\frac{U(V I)}{2}} \\ 1 & 0.840 & 2.0 & 0 & 0 \\ 11 & 0.10 & 4.0 & 0 & 0\end{array}$

The next two No. 5 cards provide the following organic feed information:

\begin{tabular}{|c|c|c|c|c|}
\hline \multirow{3}{*}{$\begin{array}{c}\text { Stage } \\
8\end{array}$} & \multirow{3}{*}{$\begin{array}{c}\text { Ziters/minute } \\
2.87\end{array}$} & $H^{+}$ & & $(V I)$ \\
\hline & & \multicolumn{3}{|c|}{ moles/liter } \\
\hline & & 0.035 & 0 & 0 \\
\hline 16 & 2.45 & 0 & 0 & 0 \\
\hline
\end{tabular}

The next No. 6 card specifies no mutual dependence of distribution data (MUT $=0)$, an $80 \%$ stage efficiency $(E F F=80.0)$, a closing tolerance of $0.1 \%$ (TOL $=0.001$ ), and an integration time (TMULT) of 0.104406 of the maximum permissible (this was carried to six places in an unsuccessful attempt to make the process time print in whole minutes). 
The No. 7 card provides:

$\mathrm{LJ}=500$ integration cycles between print profiles

$L M=2000$ integration cycles between printed material balances

$\mathrm{LI}=100$ integration cycles between steady state checks

The $\mathrm{JB}=2, \mathrm{JE}=14$, and $\mathrm{JI}=2$ cause mixer concentrations to be printed for Stages $2,4,6,8,10,12$, and 14 in addition to the first and last stages. The No. 8 card with NOPT $=3$ specifies that this is a steady state problem (rapid artificial close to steady state).

The blank card terminates input for the first problem, which is actually the first phase of a dynamic problem.

Two more phases are specified with all conditions the same as specified for the first phase with these exceptions:

- On a No. 5 card, the organic feed to the eighth stage for the second phase is changed to include concentrations of $1.0 \mathrm{gram} /$ liter of neptunium and $1.0 \mathrm{gram} / 1$ iter of uranium (nominal concentration).

- The No. 8 card for the second phase specifies that the phase should be terminated at a process time of 1440 minutes (24 hours; process time was set to zero at the end of the first phase).

- The third phase is a rapid close to steady state from the process conditions existing at the end of the second phase.

\section{OUTPUT}

Steady State Results. The first phase of the sample study (Figure 5) illustrates the output format for steady state problems. This phase brought the bank to acid equilibrium before introducing neptunium and uranium.

The format at the top provides the bank and program control input data and feed rates and feed concentrations. The efficiency $E$ is expressed as a fraction rather than the percentage (EFF) required on input. If VM, VSA, and VSO are not provided, they are set to 1.0 by the program for use in the steady state closure routine.

The profiles provide aqueous and organic concentrations leaving each stage. 
HM IT PMAK, 3.5* THP. M-NP-U, INJECT H+ AT STAGE 11

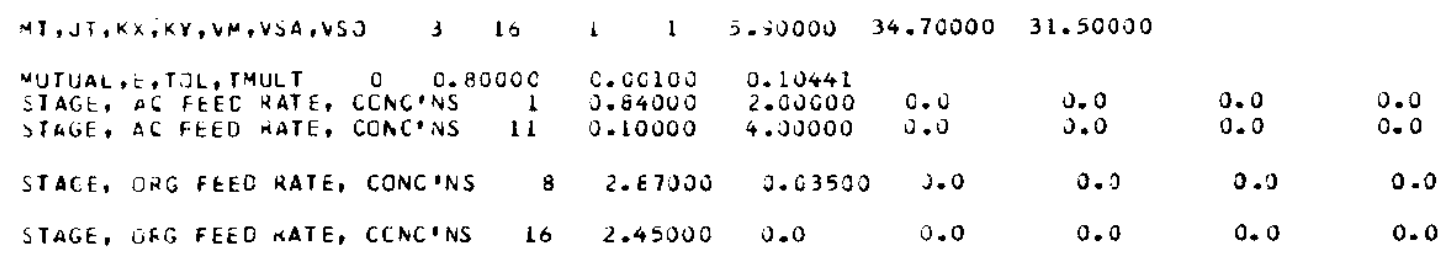

CTIME 1.00000 MIN.

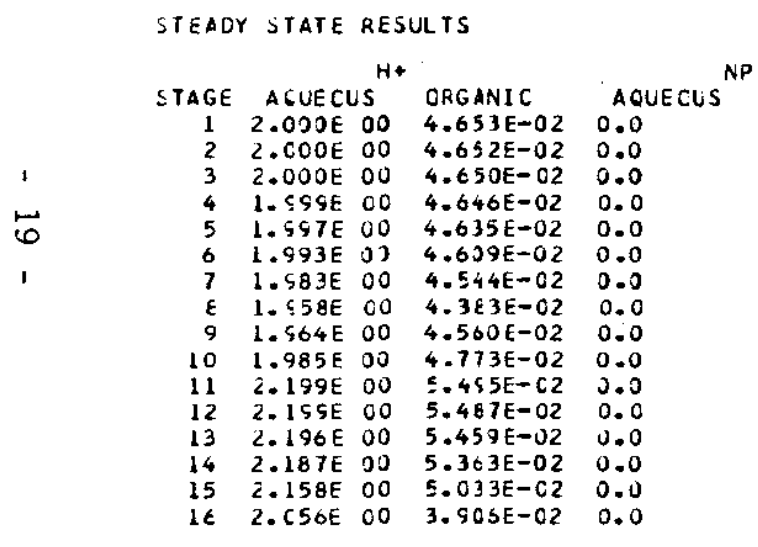

\begin{tabular}{|c|c|c|c|}
\hline CCMFCNENT & AQUECUS & $\begin{array}{r}\text { MATER IAL IN } \\
\text { ORGANIC }\end{array}$ & TOTAL \\
\hline $\mathrm{H}+$ & 0.0 & 0.0 & 0.0 \\
\hline NP & 0.0 & $0 . c$ & 0.0 \\
\hline Lvi & 0.0 & 0.0 & 0.0 \\
\hline
\end{tabular}

$\begin{array}{lll}\text { CRGANIC } & \text { AQUECUS } & \text { UVI } \\ 0.0 & \text { ORGANIC } \\ 0.0 & 0.0 & 0.0 \\ 0.0 & 0.0 & 0.0 \\ 0.0 & 0.0 & 0.0 \\ 0.0 & 0.0 & 0.0 \\ 0.0 & 0.0 & 0.0 \\ 0.0 & 0.0 & 0.0 \\ 0.0 & 0.0 & 0.0 \\ 0.0 & 0.0 & 0.0 \\ .0 & 0.0 & 0.0 \\ .0 & 0.0 & 0.0 \\ 0.0 & 0.0 & 0.0 \\ 0.0 & 0.0 & 0.0 \\ 0.0 & 0.0 & 0.0 \\ 0.0 & 0.0 & 0.0 \\ 0.0 & 0.0 & 0.0 \\ & 0.0 & 0.0\end{array}$

$\begin{array}{lll}0.0 & \text { CRGANIC } & \text { TOTAL } \\ 0.0 & 0.0 & 0.0 \\ 0.0 & 0.0 & 0.0 \\ 0.0 & 0.0 & 0.0\end{array}$

AQUECUS
$1.181 E 0 ?$
0.0
0.0
TOTAL --ERROR--

FIGURE 5. First Phase - Rapid Close to Steady State 
If the VM, VSA, and VSO fields on the No. 1 input card are punched, the inventory values are provided but the Material In, Material Out, and ERROR columns, pertinent only to dynamic output, are filled with zeros (same routine is used to print both dynamic and steady state inventories).

Dynamic Results. The output format for dynamic results (second phase of the sample study) is shown in Figures 6 and 7 : Concentration profiles are provided for each component at the frequency specified by the $L J$ parameter on the No. 7 card. The integer $L J$ is the number of integration time intervals between profiles (500 cycles or 50 minutes). The integration time interval DTIME is described on page 7 under Subroutine SETUP $(0.1$ minute in the example). The profiles include the concentration of each component in both the aqueous and organic phases leaving the mixers of the first and last stages in the bank and seven other selected stages. This is the maximum number that can be accommodated across the width of the printout.

The seven optional stages are selected with the JB, JE, and $J I$ parameters on the No. 7 card. The JB entry is the first of the seven, the JE entry the last, and the JI entry the increment between print stages. For example, JB, JE, and JI parameters of 3,15 , and 2 would print the concentrations leaving stages 3,5 , $7,9,11,13$, and 15 between the first and last stages.

Under the column labeled BANK EXIT, the profiles also show the organic concentration leaving the settier of the first stage and the aqueous concentrations leaving the settler of the last stage. In Figures 6 and 7 , the difference in aqueous concentration between Stage $16 \mathrm{mixer}$ and aqueous bank exit illustrates process holdup in the Stage 16 settler.

The LI parameter on the No. 7 card fixes the number of integration cycles between steady state checks when NOPT option 2 on the No. 8 card has been selected. If the LI field is left blank, the degree of approach to steady state is determined every 10 integration cycles (under NOPT option 3, steady state is also checked every 10 cycles unless overridden by specifying a different LI on a No. 7 card).

Component material balances (Figure 7) will also be shown on the printout at the frequency in integration cycles given by the LM parameter on the No. 7 card (2000 cycles or 200 minutes in the example). Because the program carries only seven significant figures (single precision), there will always be a measurable error in closing the material balance. The current error, although usually negligible, is shown in the last column as percent of the total feed flow for that component during the last integration cycle. 


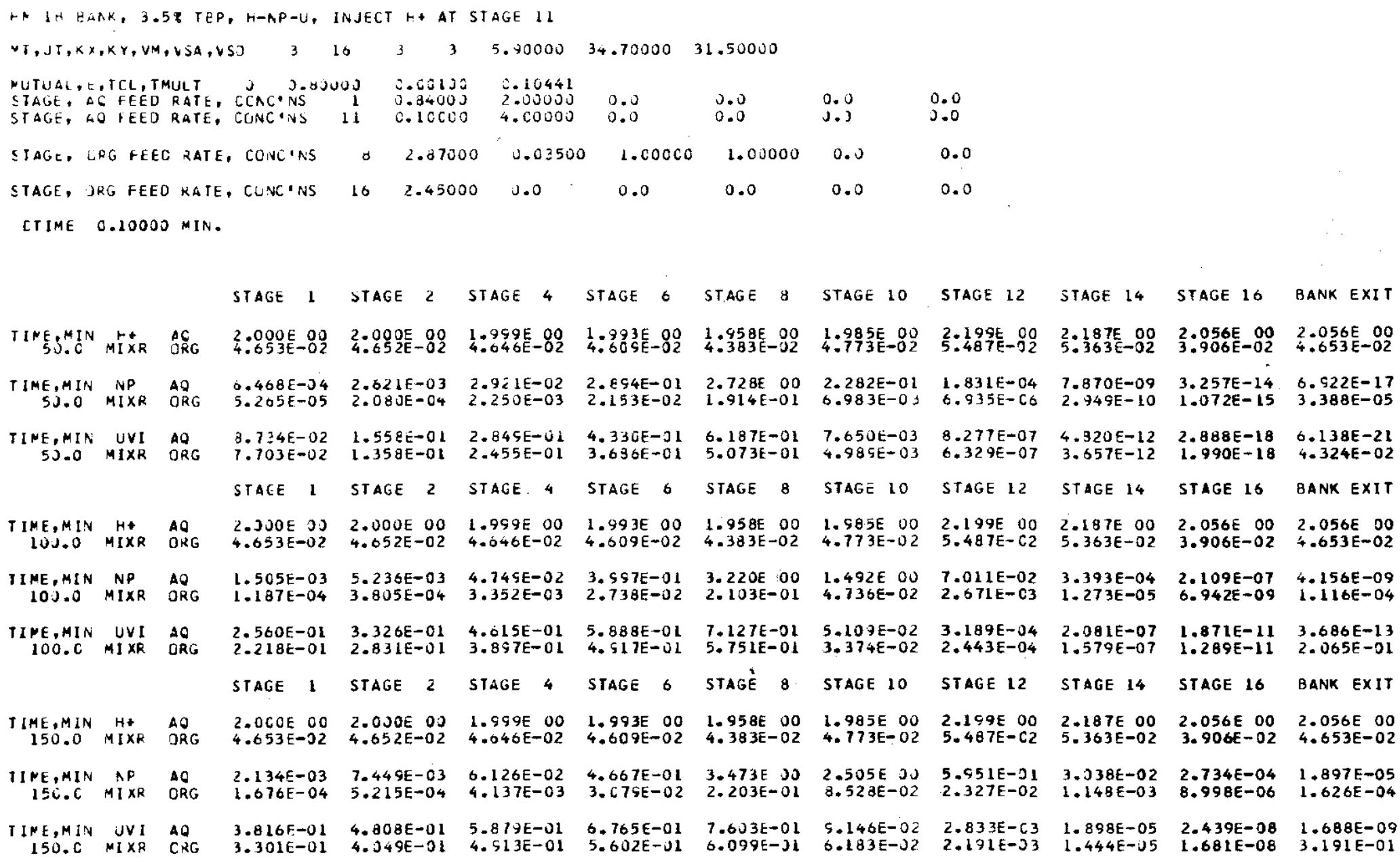

FIGURE 6. Second Phase - Dynamic Results - Beginning 


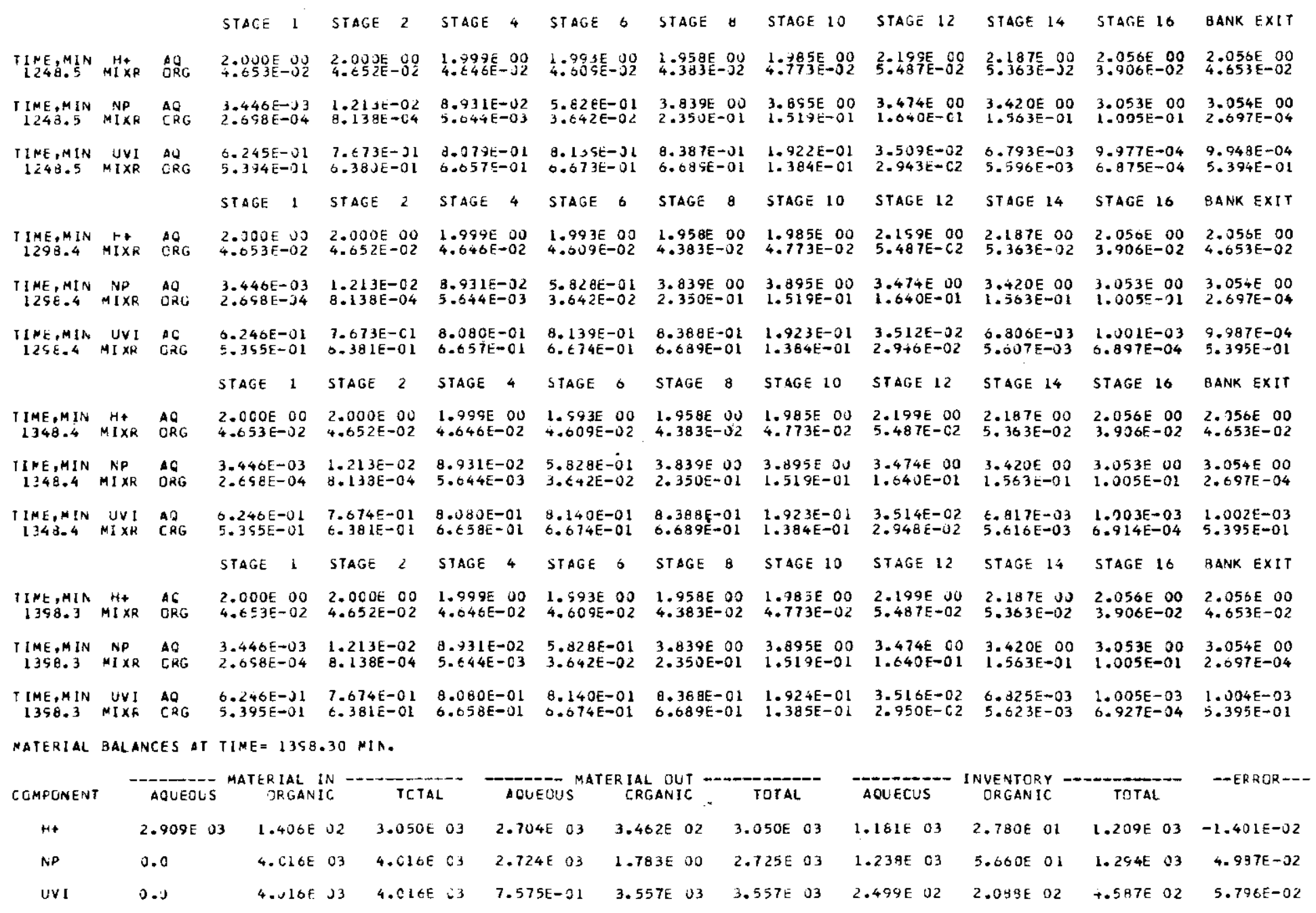

FIGURE 7. Second Phase - Dynamic Results - Ending 
When a dynamic phase closes to steady state, complete steady state profiles are printed in the form shown by Figure 5 .

In the example, the process is essentially at steady state before the end of the second phase. To confirm that, a rapid close to steady state was specified as the third phase of the study. Those results are shown in Figure 8 .

Distribution Data. The SOLVEX program summarizes the input of distribution data as shown by the compact tables in Figure 9 .

To illustrate dynamic behavior of the bank, the peak concentrations of neptunium and uranium are plotted in Figure 10 as a function of time during the second phase. The peak concentration for neptunium shifted from Stage 8 to Stage 10 after about 8 hours.

\title{
APPLICATION
} contact :

For further information concerning the SOLVEX program,

\author{
Director \\ Argonne Code Center \\ Argonne National Laboratory \\ 9700 South Cass Avenue \\ Argonne, IL 60439
}


HM 1E JANK, 2.56 TBP, H-AP-U, INJECT H+ AT STAGE 11

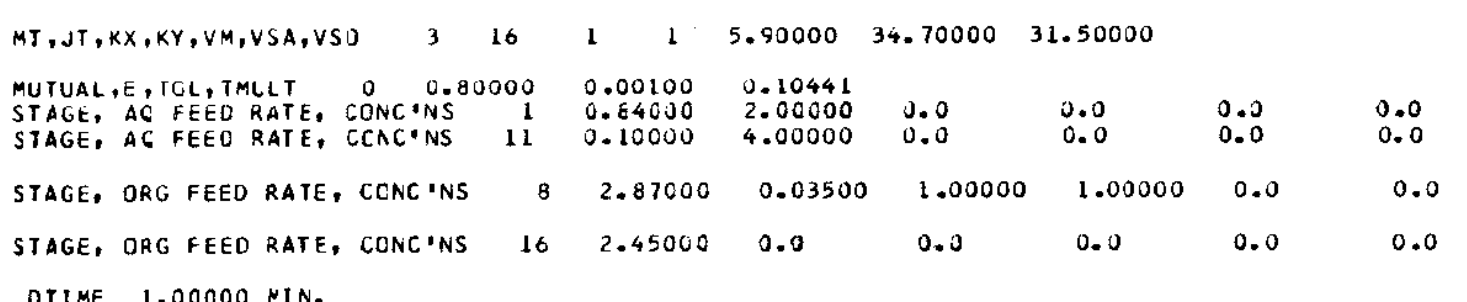

DTIME 1.00000 NIN.

STEAOY SIATE RESULIS

\begin{tabular}{|c|c|c|c|c|c|c|c|}
\hline \multirow[b]{2}{*}{ TAGE } & \multicolumn{3}{|c|}{+} & \multicolumn{2}{|c|}{$v F$} & \\
\hline & & & ORGA & CUS & ar & US & $O R$ \\
\hline & & 00 & .02 & $3.446 E-03$ & 2. & & $5.393 \mathrm{E}-01$ \\
\hline 2 & 2. & 00 & 4.6 & $1.213 E-02$ & $\varepsilon .138$ & -01 & $6.379 E-01$ \\
\hline 3 & & & $4.650 \mathrm{E}$ & $3.404 E-02$ & 2.18 & $7.999 \mathrm{E}-01$ & $6.604 E-01$ \\
\hline 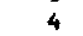 & 1. SS SE & 00 & $4.646 E$ & $8.932 E-$ & 5.6 & 8.0 & 6.65 \\
\hline 5 & & 00 & 4.6 & $2.290 \mathrm{E}-01$ & 1.43 & jl & -01 \\
\hline 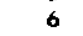 & & 00 & & $E-01$ & & & \\
\hline 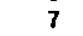 & $3 \mathrm{E}$ & 00 & 4.5 & IE 00 & 9.2 & & 6.6 \\
\hline a & i. & 00 & & E 00 & 2.3 & 01 & 01 \\
\hline & 1. & 00 & 4.5 & $E O O$ & & & 2 \\
\hline 10 & $1.585 E$ & 00 & 4.773 & $3.855 E \quad 00$ & 1.519 & 1.9 & \\
\hline 11 & 2. & 00 & 5. & $3.479 E \quad 00$ & 1. & 7. & 6. \\
\hline 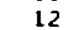 & & 00 & 5. & $3.474 E \quad C O$ & $1 . t$ & & \\
\hline 13 & & 00 & & 3.459500 & & & \\
\hline 14 & E & 00 & 5.3 & $3.419 E \quad 00$ & 1.5 & -03 & 5.64 \\
\hline 15 & & 0.5 & 5.03 & $3.313 E 00$ & 1.40 & 2.82 & $2.238 E-03$ \\
\hline 16 & $2.056 E$ & 00 & $3.906 E-02$ & $3.052 E \quad 00$ & $1.004 E-01$ & $1.011 \mathrm{E}-03$ & $6.963 E-04$ \\
\hline
\end{tabular}

\begin{tabular}{|c|c|c|c|c|c|c|c|c|c|c|}
\hline COMPONENT & AQUECUS & $\begin{array}{l}\text { MATERIAL IN } \\
\text { GRGANIC }\end{array}$ & TOTAL & AQUEDUS & $\begin{array}{l}\text { ERIAL OUT } \\
\text { CRGANIC }\end{array}$ & TOTAL & AQUEOUS & $\begin{array}{l}\text { INVENTORY } \\
\text { ORGANIC }\end{array}$ & TOTAL & --ERROR-- \\
\hline $\mathrm{H}+$ & 0.j & 0.0 & 0.0 & 0.0 & 0.0 & 0.0 & $1.181 E \quad 03$ & $2.780 E \quad 01$ & $1.209 E \quad 03$ & 0.0 \\
\hline NP & 0.0 & 0.0 & 0.0 & 0.0 & 0.0 & 0.0 & $1.237 E \quad 03$ & $5.659 \mathrm{E} \quad 01$ & $1.294 E \quad 03$ & 0.0 \\
\hline UVI & 0.0 & 0.0 & 0.0 & 0.0 & 0.0 & 0.0 & $2.498 \mathrm{E} \quad 02$ & $2.088 \mathrm{E} \quad 02$ & $\begin{array}{llll}4.586 E & 02\end{array}$ & 0.0 \\
\hline
\end{tabular}

FIGURE 8. Third Phase - Rapid Close to Steady State 
tyfe 2 tabular cistrieuticn data fur $\mathrm{H}^{+}$aegve $\mathrm{H}^{+}=0.0$

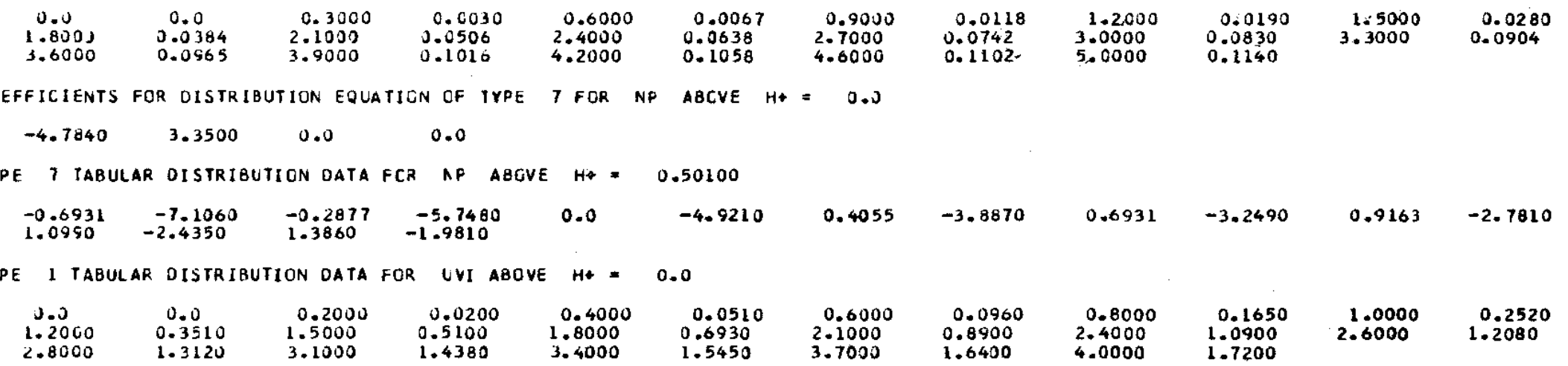

FIGURE 9. SOLVEX Summary of Distribution Data 


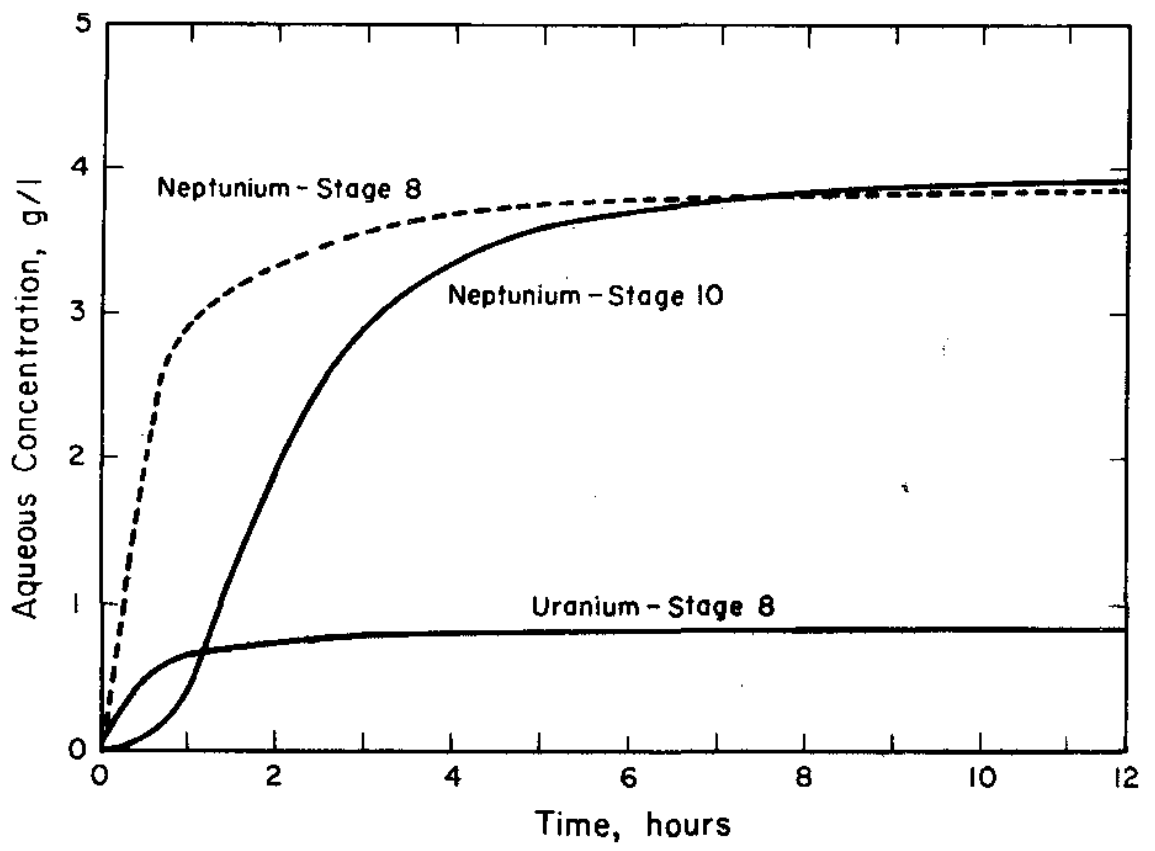

FIGURE 10. Peak Concentration Behavior During Second Phase 
The following definitions include a consistent set of dimensional units. Any other consistent set of units may be used. The terms integer and decimal refer to the form of input. Integers must be entered as a whole number, right-justified within the specified field. Decimals must include a decimal point and may be entered anywhere within the 10-column field.

$\mathrm{AF}(J) \quad$ Aqueous feed rate to stage $J$, liters per minute, decimal.

COMP1 Names for components 1 through 5; any legal alphameric through characters for the line printer.

COMP 5

$\mathrm{C}$ Concentration, units per liter of solution where units can be moles, grams, etc., decimal.

CMIN Low end of range of reference concentration over which a specific method of expressing distribution data applies, decimal.

$D_{a}^{\mathrm{O}}$

Distribution coefficient (organic-to-aqueous concentration ratio), decimal.

DTIME Integration time interval, minutes.

DUM A dummy number used to pad the unused corner of a three-variable data table (Figure 3).

EFF Stage efficiency, percent, decimal.

ETIME Process time at end of a dynamic phase, minutes, decimal.

$\mathrm{J}$ Stage number, integer.

JB,JE,JI First, last, and increment between seven selected stages for printing concentrations (output control), integers.

JT Total number of stages in bank, integer.

KOLS Total number of columns in a data table, integer.

KX (KY) Total number of aqueous (organic) zones in settlers, integer. 
LI Number of integration cycles between steady state checks, integer.

LJ Number of integration cycles between printed concentration profiles, integer.

LM Number of integration cycles between printed materia1 balances, integer.

LOOPS Number of integration cycles in dynamic phase, integer.

$\mathrm{M} \quad$ Component number, integer.

WREF Reference component number for distribution data, integer.

MREF2 Second reference component number for three-variable distribution data tables, integer.

MREF3 Third reference component number for nontransportable salting agents (the entire table applies to a specific concentration of that agent which must be greater than CMIN), integer.

MT Tota1 number of components in system.

MUT Mutual dependency parameter, integer:

0 component distributions not mutually dependent

1 distributions mutually dependent

NOPT Program options, integer:

1 dynamic, terminate phase by integration cycles or process time provided*

2 dynamic, terminate phase at steady state

3 rapid close to steady state, time reset to zero

NPHAS Phase of reference component concentration, integer:

0 organic phase

I aqueous phase

NPHAS2 Same as NPHAS but for second reference component, integer.

NROWS Total number of rows in a data table, integer.

NTYPE Form of distribution data (Figure 1), integer.

* If neither time nor cycles is provided, program execution will terminate on computer job time or maximum printer lines under the job control system at the Savannah River Plant. 


\author{
OF $(J) \quad$ Organic feed rate to stage $J$, liters per minute, decimal. \\ TMULT Integration time factor, decimal fraction less than one: \\ Integration time interval $=$ TMULT $\times$ (minimum process hold- \\ up time). \\ TOL Closing tolerance for iterations on concentrations and \\ distribution coefficients (internal program control; an \\ input of $0.001-$-one part in a thousand--will generally \\ give satisfactory results without excessive computation \\ time), decimal. \\ $u$ Dependent variable in equations and tables of distri- \\ bution data. \\ $v \quad$ Independent variable (reference concentration) in \\ equations and tables of distribution data. \\ VM Mixer volume, liters, decimal. \\ VSA Aqueous settler volume, liters, decimal. \\ VSO Organic settler volume, liters, decimal. \\ $\mathrm{XF}(\mathrm{M}, \mathrm{J})$ Concentration of component $\mathrm{M}$ in aqueous feed to Stage \\ $J$, units per liter, decimal. \\ $Y F(M, J)$ Concentration of component $M$ in organic feed to Stage \\ $J$, units per liter, decimal. \\ $z$ \\ Second independent variable (second reference concen- \\ tration) in tables of distribution data (not valid for \\ equations).
}




\section{APPENDIX B - MATHEMATICAL SIMULATION*}

DYNAMIC BEHAVIOR

Mixer Equations

By assumption:

$$
\begin{aligned}
& V_{m a}=\frac{A}{A+O} V_{m} \\
& V_{m o}=V_{m}-V_{m a}
\end{aligned}
$$

By material balance for the nth stage over the infinitesimal time interval $\mathrm{d} \theta$, the rate of change in inventory is equal to the material flow in minus the material flow out:

$$
V_{m a} \frac{d x}{d \theta}+V_{m o} \frac{d y}{d \theta}=A x_{i}+O y_{i}-A x-O y
$$

For a finite time increment (designating values at end of previous time increment by primes):

$$
\begin{aligned}
& v_{m a} \frac{\Delta x}{\Delta \theta}+V_{m o} \frac{\Delta y}{\Delta \theta}=A x_{i}+O y_{i}-A x^{\prime}-O y^{\prime} \\
& A=A_{n}=A_{n-1}+A_{n f} \\
& 0=o_{n}=o_{n+1}+o_{n f} \\
& x_{i}=\frac{A_{n-1} x_{n-1}^{\prime}+A_{n f} x_{n f}}{A_{n-1}+A_{n f}} \\
& y_{i}=\frac{o_{n+1} y_{n+1}^{\prime}+o_{n f} y_{n f}}{O_{n+1}+o_{n f}}
\end{aligned}
$$

* Terms are defined in Nomenclature, page 35. 
This estimate for the derivative is based on all values at the end of the previous time period. A better estimate can be achieved at no great sacrifice in computing time by substituting the average of the exit concentrations at the beginning and end of the current time increment for the $x^{\prime}$ and $y^{\prime}$ values in Equation $4^{\dagger}$ :

$$
V_{m a} \frac{\Delta x}{\Delta \theta}+V_{m o} \frac{\Delta y}{\Delta \theta}=A x_{i}+O y_{i}-A x_{a v}-O y_{a v}
$$

where

$$
\begin{aligned}
& x_{a v}=\frac{x+x^{\prime}}{2} \\
& y_{a v}=\frac{y+y^{\prime}}{2}
\end{aligned}
$$

These other relationships apply:

$$
\begin{aligned}
& \Delta x=x-x^{\prime} \\
& \Delta y=y-y^{\prime}
\end{aligned}
$$

By definition of stage efficiency:

$$
E=\frac{y-y_{i}}{y^{*}-y_{i}}
$$

or, solving for $y$

$$
y=E y^{*}+y_{i}(1-E)
$$

At distribution equilibrium between phases

$$
y^{*}=D x
$$

Substituting Equations 10-16 into Equation 9 and solving for $x$ yields:

$x=\frac{A\left(x_{i}-\frac{x^{\prime}}{2}\right)+0\left\{y_{i}-\frac{1}{2}\left[y_{i}(1-E)+y^{\prime}\right]\right\} \Delta \theta+V_{m a} x^{\prime}-V_{m o}\left[y_{i}(1-E)-y^{\prime}\right]}{V_{m a}+V_{m o} E D+\frac{A+0 E D}{2} \Delta \theta}$

t One could do the same for the inlet concentrations $x_{i}$ and $y_{i}$, but this would require a preliminary calculation through the entire bank on the basis of Equation 4, which would involve a significant increase in computing time. 
If $D$ is dependent upon $x$, the program iterates until the specified closing tolerance is satisfied on both $D$ and $x$. The value of $y$ is then calculated by combining Equations 15 and 16 to yield:

$$
y=E D x+y_{i}(1-E)
$$

This same procedure is repeated for each component. If distribution coefficients are mutually dependent, the entire cycle is iterated until all $\mathrm{x}$ and $\mathrm{y}$ values close to the specified tolerance.

\section{Settler Equations}

Similar equations apply to each of the several zones into which the settler is divided, each zone representing a we11-mixed tank. These zones, however, handle either organic or aqueous but not both therefore no equilibrium relationship is involved. Further, because the flow is sequential from one zone to the next, the inlet as well as the outlet concentration may be approximated more closely by the average of concentrations at the beginning and end of the time interval.

Thus, for aqueous zone 1 , the inlet aqueous concentration is the average of the exit concentrations from the mixer.

$$
x_{i, 1}=\frac{x_{m}+x_{m}^{\prime}}{2}
$$

By material balance for zone 1:

$$
\frac{v_{s a}}{k_{a}} \frac{d x_{1}}{d \theta}=A\left(x_{m}-x_{1}\right)
$$

For the finite increment:

$$
\frac{v_{s a}}{K_{a}} \frac{\Delta x_{1}}{\Delta \theta}=A\left(\frac{x_{m}+x_{m}^{\prime}}{2}-\frac{x_{1}+x_{1}^{\prime}}{2}\right)
$$

Substituting the equivalent $x_{1}-x_{1}^{\prime}$ for $\Delta x$ and solving for $x_{1}$ :

$$
x_{1}=\frac{\frac{K_{a} A \Delta \theta}{V_{s a}}\left(\frac{x_{m}+x_{m}^{\prime}}{2}-\frac{x_{1}^{\prime}}{2}\right)+x_{1}^{\prime}}{1+\frac{K_{a}^{A \Delta \theta}}{2 V_{s a}}}
$$


For the kth zone:

$$
x_{k}=\frac{\frac{k_{a} \Delta \Delta \theta}{V_{s a}}\left(\frac{x_{k-1}+x_{k-1}^{\prime}}{2}-\frac{x_{k}^{\prime}}{2}\right)+x_{k}^{\prime}}{1+\frac{k_{a}^{A \Delta \theta}}{2 V_{s a}}}
$$

Similarly, for organic phase zone 1 :

$$
y_{1}=\frac{\frac{\mathrm{K}_{\mathrm{o}} 0 \Delta \theta}{\mathrm{V}_{\text {so }}}\left(\frac{\mathrm{y}_{\mathrm{m}}+\mathrm{y}_{\mathrm{m}}^{\prime}}{2}-\frac{y_{1}^{\prime}}{2}\right)+y_{1}^{\prime}}{1+\frac{\mathrm{K}_{\mathrm{o}} \Delta \theta}{2 \mathrm{~V}_{\text {so }}}}
$$

And for zone $\mathrm{k}$ :

$$
y_{k}=\frac{\frac{k_{o} 0 \Delta \theta}{V_{s o}}\left(\frac{y_{k-1}+y_{k-1}^{\prime}}{2}-\frac{y_{k}^{\prime}}{2}\right)+y_{k}^{\prime}}{1+\frac{K_{0} 0 \Delta \theta}{2 V_{s o}}}
$$

\section{STEADY STATE BEHAVIOR}

The mixer is the only element in each stage that needs to be considered at steady state; the aqueous and organic sections of the settler will each be at a uniform concentration corresponding to the conditions at the exit of the mixer.

Calculation of steady state concentration profiles does not involve mixer and settler volumes, and these do not need to be provided unless steady state inventories are required.

Only three relationships are involved for steady state concentration profiles:

- Material balance around stage $n$ :

$$
\mathrm{Ax}_{\mathrm{i}}+\mathrm{Oy}_{\mathrm{i}}=\mathrm{Ax}+\mathrm{Oy}
$$

where 


$$
\begin{aligned}
& x_{i}=\frac{A_{n-1} x_{n-1}+A_{n f} x_{n f}}{A_{n-1}+A_{n f}} \\
& y_{i}=\frac{o_{n+1} y_{n+1}+o_{n f} y_{n f}}{o_{n+1}+o_{n f}}
\end{aligned}
$$

- Equilibrium relationship:

$$
\mathrm{y}^{*}=\mathrm{Dx}
$$

- Stage efficiency:

$$
E=\frac{y-y_{i}}{y^{*}-y_{i}}
$$

$x_{i}$ and $y_{i}$ can be calculated directly from values generated during the previous calculation cycle. Equation 29 is substituted into Equation 30 to eliminate $y^{*}$ and provide the following equation explicit in $\mathrm{y}$ :

$$
y=E D x+y_{i}(1-E)
$$

Equation 31 is then substituted into Equation 26 to solve for $x$ :

$$
x=\frac{\mathrm{Ax}_{i}+O \mathrm{OEy}_{i}}{\mathrm{~A}+\mathrm{OED}}
$$

If $\mathrm{D}$ is dependent upon $\mathrm{x}$, the program iterates to a closing tolerance on both $D$ and $x$. This final value of $x$ is then substituted into Equation 31 to provide a value for $y$.

This same procedure is repeated for each component. If distribution data are mutually dependent, the whole cycle is iterated until all $x$ and $y$ values close to the specified tolerance. 


\section{NOMENCLATURE}

Primes are used to designate values at end of previous integration cycle.

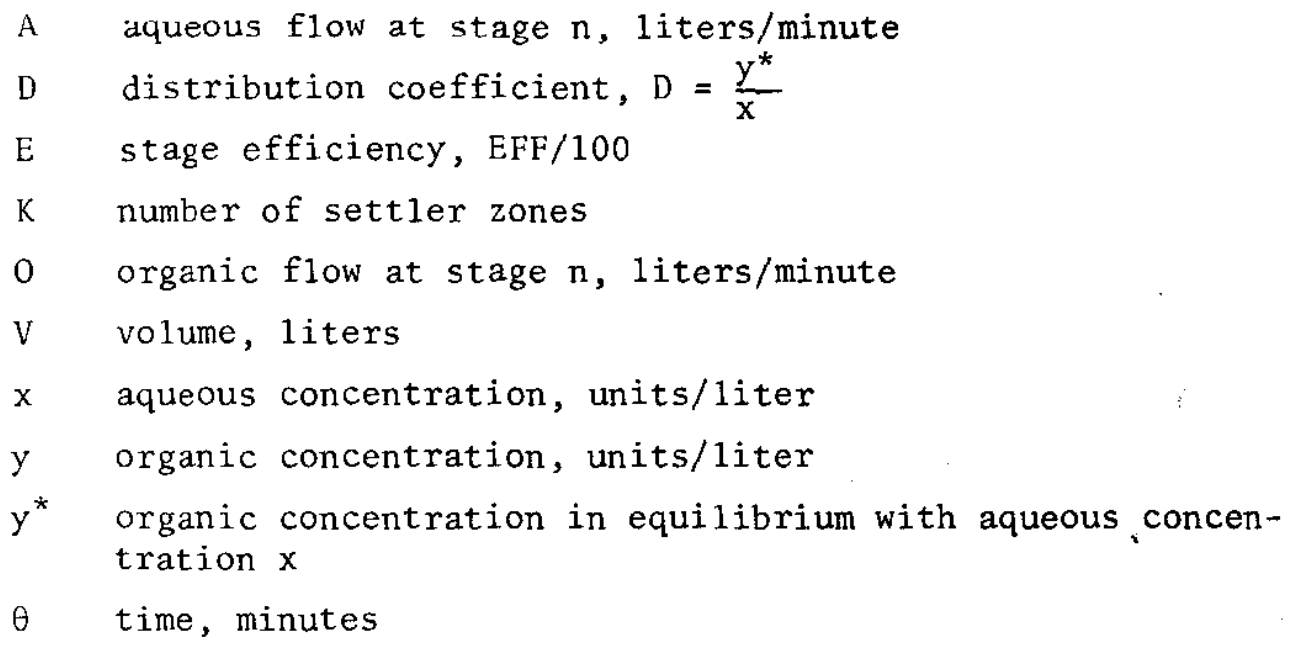

$\begin{array}{ll}\text { a } & \text { aqueous } \\ \mathrm{f} & \text { feed } \\ \mathrm{i} & \text { in (entering) } \\ \mathrm{k} & \text { zone } \mathrm{K} \\ \mathrm{m} & \text { mixer } \\ \mathrm{n} & \text { stage } \mathrm{n} \\ \mathrm{O} & \text { organic } \\ \mathrm{s} & \text { settler } \\ \mathrm{l} & \text { zone } 1\end{array}$

